\title{
Initial stimulus duration and the temporal range of apparent movement'
}

ROBERT H. POLLACK

INSTITUTE FOR JUVENILE RESEARCH, CHICAGO

The range of interstimulus intervals permitting the detection of apparent movement was investigated as a function of the duration of the initial stimulus. It was found that the interval ranges increased as duration increased from $50 \mathrm{msec}$. and declined thereafter with increasing durations up to 10 sec. The temporal course of events was discussed in relation to the microgenesis of form.

In an earlier study (Pollack, 1966) figure-ground contrast was shown to affect the temporal range of apparent movement in that the greater the contrast the greater was the range. It would be expected, therefore, that the duration of the initial stimulus would also affect the range. Sgro (1963) using flashing red lights found that the range of temporal movement as well as the threshold duration for movement declined as stimulus duration increased from $5 \mathrm{msec}$. to $100 \mathrm{msec}$. The light in his situation, however, was transmitted rather than reflected and configuration was not a factor. Since cur own earlier study, which employed light reflected from geometrical forms, clearly demonstrated the influence of figure-ground contrast and shape, variables which determine form configuration, it was expected that stimulus duration would also play a role because of its effect on the configuration of form. Therefore, as form is built up during a short temporal interval (Flavell \& Draguns, 1957; Pollack \& Chaplin, 1962) the temporal range of apparent movement would be expected to broaden to a maximum and then decline as prolonged viewing of the figural stimulus produces adaptation and subsequent breakdown of figure-ground articulation. Both Kragh (1955) and Flavell \& Draguns (1957) reported that the articulation of simple form is complete with an exposure duration of around $150 \mathrm{msec}$.

Subjects $^{2}$

Two adult $\mathrm{Ss}$, a male $\left(\mathrm{S}_{1}\right)$ and a female $\left(\mathrm{S}_{2}\right)$ served as trained Ss in all conditions of the experiment.

\section{Apparafus}

The apparent movement sequence was produced by using a three-channel electronic tachistoscope (Scientific Prototype Corporation, Model GA). Illumination as measured at the eyepiece by a Macbeth Illuminometer was $5.0 \mathrm{ft}$ 。c. for all channels.

\section{Procedure}

Since Graham (1951), reporting on earlier work by Neuhaus, indicated that the duration of only the initial stimulus was critical, the final stimulus duration was kept constant at $50 \mathrm{msec}$. The initial stimulus, a white square $12.7 \mathrm{~mm}$ on a side placed $6.35 \mathrm{~mm}$ to the left of the center of a black field was presented for 50,150 , $1000,2000,5000$, and $10,000 \mathrm{msec}$. in separate series of trials. The final stimulus was also a white square, $12.7 \mathrm{~mm}$ on a side, placed $6.35 \mathrm{~mm}$ to the right of the center of a black field. The interstimulus distance subtended a visual angle of $39^{\prime} 40^{\prime \prime}$ and the total display subtended an angle of $3^{\circ}$. A blank black field intervened for a variable interval ranging between $10 \mathrm{msec}$. and $150 \mathrm{msec}$. between the two stimuli. Viewing was binocular.

Upper and lower apparent movement thresholds were obtained from both Ss for each of the initial stimulus durations, using the method of limits. Each apparent movement range was based on 32 measures, from 2 runs, separated by at least a week, of 8 ascending and 8 descending series, run in counterbalanced order.

In each sequence, Ss were shown instances in which the stimuli were clearly successive, moving, or clearly simultaneous. They were told to say "two" when the figures were successive or simultaneous or "one" when a single figure was seen to move from left to right. Results and Discussion

Separate one-way analyses of variance on each $S$ yielded significant changes in mean temporal range as a function of initial stimulus duration for $S_{1}, F=450.11$, $\mathrm{df}=5$ and $187, \mathrm{p}<.01$, and for $\mathrm{S}_{2}, \mathrm{~F}=9.33, \mathrm{df}=4$ and 156 , $\mathrm{p}<.01$. Examination of the means for each $\mathrm{S}$ at each duration indicated an increase in temporal range between initial stimulus durations of $50 \mathrm{msec}$. and $150 \mathrm{msec}$. and a decline thereafter (See Fig. 1). A test for trend for each $S$ was carried out and yielded significant deviations from linearity for both Ss. For both Ss both quadratic and cubic trends were significant but the

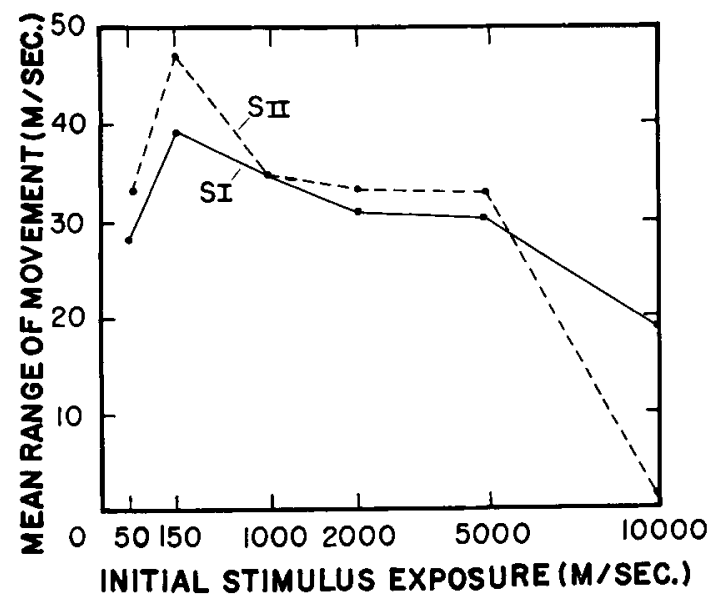

Fig. 1. Temporal range of apparent movement as a function of initial stimulus duration. 
logarithm of the appropriate quadratic equation yielded curves which better fit the data. The equation for $\mathrm{S}_{1}$ : $\log Y=1.55475+.13199(\log Z)-.09188(\log Z)^{2}$ : for $\mathrm{S}_{2} \log \mathrm{Y}=1.4625+.31448(\log \mathrm{Z})-.16720(\log \mathrm{Z})^{2}$ where $\mathrm{Z}=\mathrm{X} / \mathbf{5 0}$. The expectation that temporal range would be maximal at that point in time when the microgenetic buildup of form is completed was confirmed.

The data indicated quite clearly that when stimuli with definite shapes from which light is reflected are used, temporal range of apparent movement increases as initial stimulus duration increases up to around 150 msec. and then decreases. Range of apparent movement, therefore, depends upon those stimulus conditions which promote maximal contour strength (high figure-ground contrast and optimal duration) under conditions which promote attraction displacement of contours (Pollack, 1966), i.e. parallel contours. The similarity of these data to those obtained for backward figural masking is striking (Pollack, 1965) and probably indicates a common underlying sensory mechanism.

Comment on Beck by Jacob Beck

The Chi-square test reported by Beck (1966) is questionable because of the fact that judgments were repeated by the same Os. An over-all comparison of the constancy exhibited by adults with that exhibited by children may be obtained by classifying an $O$ as exhibiting constancy if in the majority of the five targets presented the $O$ matched the target in light and in shadow to the same gray, and as failing to exhibit constancy if the $O$ judged the target in shadow as darker in the majority of cases. When the targets were presented together on a chart, 11 adults exhibited constancy, four adults failed to do so; four children exhibited constancy, 11 children failed to do

\section{References}

Flavell, John, \& Draguns, Juris. A microgenetic approach to perception and thought. Psychol. Bull., 1957, 54, 197-217.

Graham, C. H. Visual perception. In S. S. Stevens (Ed.), Handbook of experimental psychology. New York: Wiley \& Sons, 1951.

Kragh, Ulf. Actual genetic model of perception personality. Lund, Sweden: C. W. Gleerup, 1955.

Pollack, R. H. Backward figural masking as a function of chronological age and intelligence. Psychon. Sci., 1965, 3, 65-66.

Pollack, R. H. Effect of figure-ground contrast and contour orientation on the temporal range of apparent movement. Psychon. Sci., 1966,4 (12), 401-402.

Pollack, R. H., \& Chaplin, M. R. Some methodological problems in microgenetic investigation. Amer. J. Psychol., 1962, 75, 495499.

Sgro, Frank J. Beta motion thresholds. J. exp. Psychol., 1963, $66,3,281-285$.

\section{Notes}

1. This research was supported by Grant No. HD 01433 awarded by the National Institute of Child Health and Human Development. 2. Acknowledgement is given to Mr. Gene Skoff and Miss Thais Golden who served as subjects and experimenters. so. A two-tailed Fisher test shows that the probability of the observed values under the null hypothesis is .026 (Finney, 1948). When the targets were presented singly, the difference between the number of adults and children classified as exhibiting constancy did not differ significantly.

\section{References}

Beck, J. Age differences in lightness perception. Psychon. Sci., 1966, 4, 201-202.

Finney, D. J. The Fisher-Yates test of significance in $2 \times 2$ contingency tables. Biometrika, 1948, 35, 145-156. 